\title{
Melinda J. Smith: Teaching Playskills to Children with Autism Spectrum
}

\author{
DRL Books, New York, NY, 2001, 174 pp
}

Stephanny F. N. Freeman

Published online: 20 June 2009

(c) The Author(s) 2009. This article is published with open access at Springerlink.com

Well done Dr. Smith. Although you state, "I am not a formally accredited expert and I do not have any data or evidence," you provided a very useful and well-framed resource for professionals and parents. It is rare that a book written by a parent/mental health professional can combine the use of practical language and personal experience with strong evidenced-based theory to provide a hands-on guide for anyone working with a child with autism. Parents especially need this book, Teaching Playskills to Children with Autism Spectrum Disorder" as so many frequently state, "I forgot how to play," or "I don't know how-I was never a big 'player' when I was a child." Professionals can use this book to guide their own framework in play instruction. At first glance, it looked as if this book was a basic "how to" guide on activities of play-for the very naïve parent which is mostly what is available in the popular literature. Instead, however, this book provides a strong theoretical basis, developmental approaches to curriculum, and practical suggestions and resources that are appropriate for therapeutic environments as well as the home/family environment.

Most impressive was Chapter 1. Clearly Dr. Smith has educated herself on the wealth of very specific and discrete knowledge about different theories of play, different approaches to teaching play, different categories of play opportunities, and sequences of play. Empirical articles in the field of social development and play in both the populations of children with typical development and children with autism are frequently very specific and pointed towards one particular domain (e.g., toy play, peer play sequences,

S. F. N. Freeman $(\bowtie)$

UCLA Neuropsychiatric Hospital-Early Childhood Classroom,

740 Westwood Plaza, Los Angeles, CA, USA

e-mail: sfreeman@mednet.ucla.edu specific social skills such as turn taking). Dr. Smith synthesized these findings in a clear and concise manner. She provided first a framework: Childhood play includes physical play, social play, and cognitive play. She then framed play in a developmental perspective that takes a hierarchical integrative pathway. She addressed splinter skills, being in touch with reality and what play in "typical" children looks like, and even mentioned the importance of acknowledging the difference between using play as a teaching tool (e.g., to develop language, to role play, to teach manners) versus teaching play to play. Indeed, her Chapter 1 could serve as a good introduction to a course on play in autism.

Within the "Teaching Techniques" subsection of Chapter 1, Dr. Smith paid appropriate attention a number of extremely important points for instruction. First, the consideration of development-Dr. Smith emphasizes the use of "developmentally appropriate" targets. These are targets that the families/therapists choose as a place to begin instruction. Dr. Smith identifies the sequences of play, the reality of what typical children are doing at a certain age as well as taking gender preferences into account. Further, she considers the basic building blocks of social learningimitation and joint attention. Second, Dr. Smith bases her theoretical framework on teaching within the structure of Applied Behavior Analysis, but she emphasizes motivation, reinforcement, and generalization-critical components of strong play intervention research. She ensures that her chapter avoids the conflicts of "what method works the best" by instead describing an integration of many different methods. She has compiled a number of different approaches and attempted to provide a user-friendly guide for the willing but resource-thin parent.

As mentioned, the developmental approach is inherent throughout the book as each chapter builds upon skillsbeginning with imitation skills as the initial sequence. This 
fits the characteristics of the core deficiencies in autism (imitation, play, joint attention). She then covers simple construction which accurately follows play sequences well established in empirical research. Her terminology (well defined) throughout the book allows parents to truly shift their thinking about toys and understand their usefulness in development. She uses such terms as "close-ended toys" to show parents that "imagination" would be difficult with these types of toys (vs. "open-ended"). The behavioral approach (which has been empirically validated as an effective teaching technique) is also inherent throughout the book. She identifies breaking down skills to component parts, using 1:1 sessions to teach and practice verbal initiations and transitions, using strategies such as reinforcement and rewards (differential reinforcement of certain behaviors, rewarding other children, etc.), backward chaining, and she identifies the use of prompting in a hierarchical manner. A third approach is one that is also somewhat child-centered. She emphasizes motivation and not being afraid of a child's interest-yet building on that interest without allowing the child to completely dictate the session such that nothing gets accomplished. Even her chapter on using television is surprisingly appropriate and "practical" for families (vs. "TV is bad! Don't use it"). Finally, Dr. Smith uses these structured activities to eventually lead to the integration of skills first with adults and then with peers and groups.
Dr. Smith's goal was clearly met. As the subtitle indicates, she provides a practical guide for parents with a wealth of resources and ideas for developmentally appropriate targets, materials, teaching style, and guidance/support for generalization. She provides targets for any professional or therapists that include systematic and sequential approaches to instruction. She immerses parent report for external validation; and from a researcher's perspective Dr. Smith's ideas are all extremely strong. One point throughout the book is that we as parents and professionals should not expect our children with autism to be $100 \%$ appropriate in the social world when children with typical development are not so-yet this book helps a parent strive for that. Indeed, it is important for us to strive for children with autism to at least have knowledge of perfect, or at least exemplary, social skills such that practice towards such skills becomes easier. I highly recommend this book as it can help parents and practitioners alike break down the large conceptual picture of "playing" for children with autism into understandable parts, then to break down those parts into understandable sequences, and then have in-hand the materials and methods to teach play effectively.

Open Access This article is distributed under the terms of the Creative Commons Attribution Noncommercial License which permits any noncommercial use, distribution, and reproduction in any medium, provided the original author(s) and source are credited. 